\title{
Assessment of Patient Safety Culture among Health Care Workers in Beni-Suef University Hospital, Egypt
}

\author{
Ekram M. El-Shabrawy, Manal M. Anwar, Zahra'a Mohammed Mostafa
}

Department of Public Health and Community Medicine, Faculty of Medicine, Beni -Suef University

Received: March $2016 \quad$ Accepted: June 2016

\begin{abstract}
Background: Patient safety is an essential component in the quality of patient care. It remains a challenge for developing countries. Assessment of patient safety culture in healthcare organizations is becoming an integral component to improve patients' safety. Aim: To assess the perceptions of patient safety culture attitude among health-care workers in Beni-Suef University hospital. Participants and Methods: A cross sectional study was conducted from January till December 2015 using the Hospital Survey on Patient Safety Culture (HSOPSC) self-administered questionnaire which includes 12 dimensions on 500 university hospital staff members in Beni-Suef University hospital with a response rate of $84.6 \%$ (423/500). Results: The overall mean positive response rate for patient safety in Beni-Suef University Hospital was 39.3\%. Healthcare workers had lower perceptions about patient safety culture. Only two dimensions showed positivity above 50\%. The highest positive mean score dimension was "Teamwork within units" $(57.4 \%)$ while the lowest positive mean score dimension was "Frequency of events reporting" $(23.2 \%)$. Patient safety grade in relation to the staff position showed significant difference between the studied groups $(\mathrm{p}=0.009)$. Conclusion and Recommendations: Healthcare workers appear to have a lower perception of patient safety culture. Training of healthcare workers on patient safety and broad based research are highly recommended in order to improve patient safety culture. Patient safety needs to be incorporated into the education of health professionals across the spectrum of healthcare. There should be a blame-free system for identifying threats to patient safety, sharing information and learning from events.
\end{abstract}

Key words: Patient safety culture, hospital, health care workers, reporting. Corresponding author: Manal M. Anwar, MD E-mail address: M_anwarabdo@yahoo.com

\section{Introduction}

Patient safety; a healthcare discipline, is defined as 'the prevention of harm caused by errors of commission and omission' with special emphasis on reporting, analysis, and prevention of medical errors that often lead to an adverse health care event. ${ }^{1,2}$ People in any community are exposed to preventable medical errors; a rate that ranges from $20-42 \% .^{3}$ The undue consequences of such medical errors require studies focusing on patient safety, generally concentrating on hospital environments. $^{4,5}$

The strategy of a safety patient culture starts with an evaluation of the present safety level in an institution (safety precautions implemented without proper assessment may be costly with unpredicted new risks). ${ }^{6}$ Tools developed for evaluation of the patient safety culture are many ${ }^{7-9}$ with most of them covering five common dimensions: leadership, policies and procedures, staffing, communication and reporting. ${ }^{10}$ 
Health organizations such as the Accreditations Achievement and Patient Safety Friendly Hospital Initiative, aimed to improve patient safety culture and to deal with the unsafe healthcare practices in Eastern Mediterranean Region - World Health Organization office (WHO). ${ }^{11}$

In March 2007, the Eastern Mediterranean Regional Office (EMRO) - WHO, conducted a "Patients for Patient Safety" regional workshop in Cairo that concluded on the importance of engaging patients in shaping the healthcare system. ${ }^{12}$ In Egypt, different studies highlighted the need to improve the patient safety culture among healthcare providers. Two studies from University Hospitals in Alexandria; first one for 400 clinical staff members assessing patient safety and their work settings. It was observed that the participants in the ICUs had the highest overall mean score on patient safety items $(3.57 \pm 0.34)^{13}$, while the other study revealed an overall dimension of safety culture mean score among 165 nurses of $3.33 \pm 0.58 .^{14}$ In Cairo University Teaching Hospitals, a study among 400 healthcare providers revealed that dimensions of the overall perceptions of safety mean scores were significantly highest for physicians 6.2 \pm 1.2 that differed from scores of nurses $5.7 \pm 1.3$ and paramedical personnel 5.6 $\pm 1.4 .^{15} \quad$ In Ain-Shams University hospitals, a study among 510 physicians, nurses, pharmacists, technicians and laborers revealed a highest mean composite positive score among the 12 dimensions was for the organizational learning for continuous improvement (78.2\%), followed by teamwork $(58.1 \%)$. The lowest mean score was for the dimension of non-punitive response to error $(19.5 \%){ }^{16}$

Similarly; measurement health care personnel (managers, physicians, nurses, pharmacists, and technicians) attitudes towards patient safety in 35 primary heath care centers in three governorates in Egypt, revealed an overall mean for all questions and respondents of $3.89 \pm 0.59$. Safety climate mean was $3.64 \pm 0.67$. The percentage of respondents viewing the safety climate as positive was $36 \% .^{17}$

Medication errors (MEs) are among the most common medical errors, harming about 1.5 million people every year. Medication errors are main contributors to adverse events to hospitalized patients. ${ }^{18,19}$ In addition to weakening the patients' confidence in medical services, MEs also impose substantial costs between US\$ 6 billion and US\$ 29 billion per year. Voluntary reporting by health care providers depends on their awareness, hence many errors remain frequently unreported. ${ }^{20}$

In Egypt, studies addressing medication errors were reported. In one study, 1107 of the medication orders $(78.1 \%)$ had at least one prescription error. ${ }^{21}$ In another descriptive analysis of medication errors reported to the Egyptian national online reporting system, out of the 12000 valid reports that were analyzed, prescription errors were the most common type of MEs (54\%), followed by monitoring $(25 \%)$ and administration errors $(16 \%){ }^{22}$ In another confirmatory study, the commonest medication errors was during ordering and prescription stage (38.1\%), followed by the administration stage, $(20.9 \%)$. Errors during monitoring, preparation and dispensing were: $(18.3 \%), \quad(12.3 \%)$ and $(10.4 \%)$, respectively. ${ }^{23}$

The objectives of this study were to assess patient safety culture of healthcare workers in Beni-Suef University hospitals, and to suggest proactive actions aiming at improving attitudes and policies to reinforce and sustain commitment to a safer patient care environment.

\section{Subjects and Methods}

Study locality: This study was carried out in a tertiary level care hospital (Beni- 
Suef University hospital) - Beni Suef Governorate - Egypt.

Study design: This is a descriptive crosssectional study.

Sample size: A total of 398 hospital health care workers participated in the study including physicians, nurses and technical staff, and non-medical staff.

Sample method: Data was collected from January till December 2015 using a Hospital Survey on Patient Safety Culture (HSOPSC) questionnaire with 12 dimensions distributed for 500 university hospital health care workers with a response rate of $84.6 \%$ (423/500). After thorough revision of the filled survey questionnaires; 25 of them were excluded (incomplete data or answers repetition). Finally, 398/500 (79.6\%) questionnaires were available for data analysis.

Distribution of $398 \mathrm{HCWs}$ was as follows: $52.3 \%$ nurses and technical staff (208/398), 39.4\% physicians (157/398) and $8.3 \%$ were non-medical staff (33/398).

Hospital Survey on Patient Safety Culture (HSOPSC) questionnaire was prepared in Arabic language and used for data collection and analysis. This questionnaire was tested by a pilot study before data collection on $50 \mathrm{HCWs}$ working in Beni-Suef University hospital during January, 2015. The purpose of that pilot study was to ensure the clearness and easiness of the questions.

Results were included in the study.

Study tools and data collection technique: The HSOPSC is a survey that assesses patient safety culture based on the perspectives of health care workers. It was used to measure patient safety culture dimensions in the whole hospital and some specific units. HSOPSC included 12 safety culture dimensions: 10 patient safety culture dimensions (included seven unit-level dimensions and three hospital level dimensions) and 2 outcome dimensions. The total number of items were 42 of a 5-point Likert scale ranging from $1=$ 'strongly disagree' to 5 $=$ 'strongly agree'.

The domain scores were calculated using the following formula:

Total number of positive responses to the items in the dimension

Total number of items in each dimension

- Dimensions with positive response rates of $75 \%$ or above were identified as strengths.

- Dimensions with at least $50 \%$ positive response rate were identified as potential for improvement.

- Dimensions with less than 50\% were identified as weaknesses.

In addition, the questionnaire included a demographic characteristics part, which included age, gender, educational level, years of experience in current hospital, years of experience in current unit, total weekly working hours.

\section{Data Analysis}

The data collected were coded then analyzed using the SPSS version 18 (Statistical package for social science). Descriptive statistics such as frequency and percentage were used for data summarization. Suitable statistical tests were used (Chi-square $\left(\chi^{2}\right)$, one way ANOVA and Spearman's correlation), Pvalues equal to or less than 0.05 were considered statistically significant.

Ethical considerations: To ensure privacy, dignity and integrity, the used questionnaire was anonymous. In addition; official permissions were obtained from the faculty of Medicine Beni-Suef University hospital. The questionnaires included explanations about the purpose of the study, confirmation of confidentiality of data and assuring that it will never be used for purposes other than scientific research.

\section{Results}

Among the 398 participants included in this study; Para-medical personnel (nurses, technical staff) constituted the 
highest percentage $(52.3 \%)$, followed by physicians $(39.4 \%)$ and only $(8.3 \%)$ of the participants were non-medical personnel.

Females constituted $64.2 \%$ (256/398) - as all nurses were females- compared to $35.8 \%$ (142/398) male participants. Mean age of the whole group was $30 \pm 7.69$ (range: 19-57). Among the study participants $36.5 \%$ held Postgraduate degree, while $32 \%$ were university/college graduates, 153 (38.4\%) had a work experience of 1-5 years in their current hospital, and 184 (46\%) had work experience for 1-5 years in their current unit. Study participants with an average working hour between 20-39 hrs./ week constituted 149 (37\%).

Those working in Medicine constituted (20.1\%), followed by $(15.6 \%)$ in Surgery, and those working across units (no specific unit) were (4.5\%). (Table 1)

The overall average positive response score of safety culture in Beni-Suef University Hospital is (39.29\%). Except for Supervisor/manager Expectations \& Actions Promoting Safety (53.5\%) and Teamwork within Hospital Units (57.4\%), all other safety culture dimensions showed positivity $<50 \%$ with the lowest positivity $(23.2 \%)$ for the frequency of events reporting. (Table 2)

Patient safety grade in relation to the staff position showed significant difference between the study participants $(\mathrm{p}=0.009)$, with no significant difference between number of events reported over the past 12 months $(\mathrm{p}=0.074)$. (Table 3$)$ Correlation between frequency of events reporting and overall perception of patient safety and the remaining 10 components showed that the dimension frequency of events reporting showed positive correlation with 9 dimensions; strongest of which was for communication openness ( $\mathrm{r}=0.362)$ while teamwork within hospital units showed the weakest correlation $(\mathrm{r}=0.185)$. As for the dimension overall perception of safety, there was positive correlation with 9 dimensions, strongest of which was for handoffs \& transitions ( $\mathrm{r}=0.531)$ while the weakest was that for management support for patient safety $(\mathrm{r}=0.142)$. (Table 4)

\section{Discussion}

Patient safety being a critical component in healthcare quality; health care organizations continually strive to improve the recognition and importance of establishing a culture of patient's safety. ${ }^{24}$ Tools for Safety culture assessment need an organization with the basic understanding of safety-related perceptions and attitudes of both managers and staff. ${ }^{25}$ This study is the first to systematically assess patient safety culture in Beni-Suef University hospital.

As regard the percentage of study participants staff category in relation to their hospital unit; Para-medical category $(52.3 \%)$; physicians $(39.5 \%)$ and nonmedical staff $(8.3 \%)$ (Table-1). Similar studies showed reported percentages comparable to ours ${ }^{26}$ with nurses constitute $(57.8 \%)$ of respondents; while in a study in Cairo university hospitals physicians represented $(54.8 \%)$ of respondents. $^{15}$

The overall patient safety culture score in this study was $(39.3 \%)$, which is lower than that reported by the Agency for Healthcare Research and Quality AHRQ, $2014 \quad(64 \%)^{27}$, Palestine (63.5\%), Saudi Arabia (60\%), Lebanese private hospitals, $\quad(72.5 \%)^{28}$, and Hospital Survey on Patient Safety Culture- 2012 in China (63\%). ${ }^{29}$

A possible explanation for the discrepancy of our result and others is the deficiency of patient safety culture awareness, HCWs training programs and institutional performance improvement strategy in Beni-Suef University Hospital (Table 2).

In the current study; percentage of paramedical and non-medical personnel were the highest (40-42\%) that reported 
"Excellent/Very good" patient safety grades followed by physicians $(30 \%)$. While for the acceptable grade; physicians $(43 \%)$ followed by nonmedical and paramedical personnel (33$39 \%$ ) was observed (Table3). These results are comparable to a similar national study report. ${ }^{15}$ Findings are contradictory to lower percentages internationally reported for the overall acceptable grade for patient Safety (range: $13 \%-35.2 \%$ ) and very much lower for the Excellent/Very Good" grade (range: $58-73 \%)^{28-30}$, reflecting the defective education and training of our health care workers.

The mean Number of Events Reported among the study participants were 1.90 $\pm 1.67,1.73 \pm 1.52$. $2.42 \pm 2.09$ for physicians, Para-medical and nonmedical staff respectively; findings which is not matching with a similar national study reporting a higher mean of event reporting with significantly highest mean scores for physicians $(4.6 \pm 1.4)$ followed by nurses (3.7 \pm 1.2$)$ and paramedical personnel $(3.5 \pm 1.2)^{(15)}$ and Saudi study reporting $3.0 \pm 1,3.7 \pm 1$, $3.2 \pm 0.9$ for physicians, Para-medical and non-medical staff respectively. ${ }^{30} \mathrm{~A}$ finding that might reflect the defective training and negligence of Beni-Suef HCWs of the importance of patient safety event reporting.

As regard the correlation between frequency of events reporting and the 10 composites of patient safety, 9 dimensions showed positive correlation with frequency of events reporting strongest of which was observed for communication openness $(\mathrm{r}=0.362)$ while teamwork within hospital units showed the weakest correlation $(\mathrm{r}=0.185)$ (Table 4). Contradictory results were from Middle East showing positive correlation between frequency of events reported and the 10 composites of patient safety; strongest correlation was observed for feedback and communication about error (Pearson $r=$
0.413) ${ }^{31}$ and teamwork across hospital units ${ }^{26}$, while the weakest correlation was for on supervisor manager expectations to promote patient safety (Pearson $r=0.081) .{ }^{31}$ In addition, there was positive correlation between the dimension overall perception of safety and 9 dimensions of patient safety in the current study, strongest of which was for handoffs \& transitions ( $\mathrm{r}=0.531)$ while the weakest was that for management support for patient safety $(\mathrm{r}=0.142)$ (Table 4). Findings are in agreement with Higher scores on hospital handoffs and transitions ${ }^{26}$ and not in agreement with the reported strongest correlation for hospital management support for patient safety (Pearson $r=0.352$ ) and weakest for non-punitive response to error (Pearson $r=0.176){ }^{31}$

\section{Conclusion and Recommendations}

Perceptions of patient safety culture in Beni-Suef university hospital were unexpectedly low. Dimensions with lowest positivity were: frequency of event reporting, non-punitive response to errors, communication openness, and feedback and communication about errors. Patient safety culture was considered to be just acceptable by most of the respondents. It is thus recommended to initiate an interventional effective patient safety program by incorporating it into the education of health professionals which should continually be supported, and maintained organization-wide, among health care personnel to improve safety and quality.

\section{Reference}

1. World Health Organization. "World Alliance for Patient Safety". WHO,2012.URL:http://www.who.int/featu res/factfiles/patient_ safety/ en/index.html Retrieved January, 2012.

2. Institute of Medicine (IOM). Patient Safety: Achieving a New Standard for Care. Washington, DC: National Academy Press, 2004. 
3. Blendon RJ, DesRoches CM, Brodie $M$ et al. Views of practicing physicians and the public on medical errors. N Engl J Med 2002; 347:1933-40.

4. WHO. Call for More Research on Patient Safety. http://www. who.int/mediacentre/news/releases/2007/ pr52/en/index.html.

5. Castle NG. Nurse Aides' ratings of the resident safety culture in nursing homes. Int J Qual Health Care 2006; 18:370-6

6. Warburton RN. Patient safety-how much is enough? Health Policy 2005;71:223-32.

7. Schutz AL, Counte MA, Meurer S. Development of a patient safety culture measurement tool for ambulatory health care settings: analysis of content validity. Health Care Manag Sci 2007;10:139-49.

8. Kirk S, Parker D, Claridge $\mathrm{T}$ et al. Patient safety culture in primary care: developing a theoretical framework for practical use. Qual Saf Health Care 2007;16:313-20.

9. Emergency Care Research Institute (ECRI). Healthcare risk control: culture of safety. Risk and quality management strategies 21, 2005. www.ecri.org.

10. Colla JB, Bracken AC, Kinney LM et al. Measuring patient safety climate: a review of surveys. Qual Saf Health Care 2005;14:364-6.

11. Siddiqi S, Elasady R, Khorshid I et al: Patient safety friendly hospital initiative: from evidence to action in seven developing country hospitals. International Journal for Quality in Health Care; 2012; Volume 24, Number 2: pp. 144-151

12. World Health Organization. Patients for Patient Safety Regional Workshop: 26th - 28th March 2007 -Cairo, Egypt. URL: $\quad$ http://www.who.int/patient safety/events/07/28_03_ 2007/en/index .html Retrieved January, 2012.

13. Abbas HAE, Bassiuni NA and Baddar FM. Perceptions of front-line healthcare provides towards patient safety: a preliminary study in a University hospital in Egypt. Topics in
Advanced Practice Nursing eJournal.2008;8(2): $\quad$ Medscape.URL: http://www.medscape.com/ viewarticle/ 570921 Retrieved February, 2012.

14. Abdou HA, and Sabir KM. A baseline assessment of patient safety culture among nurses at Student University hospital. World Journal of Medical Sciences, 2011; 6 (1): 17 - 26.

15. Abdelhai R, Abdelaziz BS, and Ghanem SN. Assessing Patient Safety Culture and Factors Affecting It among Health Care Providers at Cairo University Hospitals. Journal of American Science 2012;8(7).

16. Aboul-Fotouh AM, Ismail NA, Ez Elarab HS, Wassif GO. Assessment of patient safety culture among healthcare providers at a teaching hospital in Cairo, Egypt.East Mediterr Health J. 2012 Apr;18 (4):372-7. PubMed PMID: 22768700.

17. Nabhan A and Ahmed-Tawfik MS. Understanding and attitudes towards patient safety concepts in obstetrics. Int $\mathbf{J}$ Gynecol Obstet. 2007; 98: 212 - 216.

18. Bates D. W., Boyle, D., Vander, V. M., Schneider, J., \& Leape, L. Relationship between medication errors and adverse drug events. J Gen Intern Med.1995;10, 199-205. http://dx.doi.org/ 10.1007/BF02600255

19. Bates, D. W., Miller, E. B., Cullen, D. J., Burdick, L., Williams, L., Laird, N. P., Leape, L. Patient risk factors for adverse drug events in hospitalized patients. ADE prevention Study Group. Arch Intern Med, 1999;159(21), 25532560. http://dx.doi.org/10.1001/ archinte. 159.21.2553

20. World Health Organization. Reporting and learning systems for medication errors: The role of pharmacovgilence centers. Retrieved from http://apps. who.int/medicinedocs/documents/s $21625 \mathrm{en} / \mathrm{s} 21625 \mathrm{en} . \mathrm{pdf}, 2014$.

21. Alagha $\mathrm{H}$, Badary $\mathrm{O}$, Ibrahim $\mathrm{H}$, Sabri N. Reducing prescribing errors in the paediatric intensive care unit: an 
experience from Egypt. Acta Paediatr; 2011, 100:e169-e174

22. Shehata, Z. H., Sabri, N. A., \& Elmelegy, A. A. Descriptive analysis of medication errors reported to the Egyptian national online reporting system during six months. J Am Med Inform Assoc; 2015 http://dx.doi.org/10. 1093/jamia/ocv096

23. Kamal Elden1 N M \& Ismail A. The Importance of Medication Errors Reporting in Improving the Quality of Clinical Care Services. Global Journal of Health Science; 2016,Vol. 8, No. 8; 243251

24. Sorra JS and Nieva VF. Hospital Survey on Patient Safety Culture. (Prepared by Westat, under Contract No. 290-96-0004). AHRQ Publication No. 04-0041. Rockville, MD: Agency for Healthcare Research and Quality. September 2004.URL: www.ahrq.gov/ qual/patientsafetyculture/hospcult.pdf.

Retrieved September, 2011.

25. Pronovost $P$ and Sexton B. Assessing safety culture: guidelines and recommendations. Quality \& Safety in Health Care. 2005; 14: 231 - 233.

26. EL-Jardali F, Jaafarm M, Diamssi H, Jamal D and Hamdan R The current state of patient safety culture in Lebanese hospitals: a study at baseline International Journal for Quality in Health Care 2010; Volume 22, Number 5: pp. 386-395 Advance Access Publication: 10 August 2010

27. Sorra J, Famolaro T, Dyer N, Nelson D, Smith SA: Hospital Survey on Patient
Safety Culture: 2012 User Comparative Database Report. Prepared by Westat, Rockville, MD, under Contract No. HHSA 290200710024C. AHRQ Publication No. 12-0017. Rockville,MD: Agency for Healthcare Research and Quality; 2012. http://www.ahrq.gov/ professionals/quality-patient-safety/ patient safety culture/ hospital/2012/ index.html

28. Hamdan $\mathrm{M}$ and Saleem A Assessment of patient safety culture in Palestinian public hospitals International Journal for Quality in Health Care 2013; Volume 25, Number 2: pp. 167-175 10.1093/intqhc/mzt007 Advance Access Publication: 3 February

29. Nie Y, Mao X, Cui H, He S, Li J and Zhang $M$ Hospital survey on patient safety culture in China Nie et al. BMC Health Services Research, 2013; 13:228. http://www.biomedcentral.com/14726963/13/228.

30. Al-Ahmadi TA. Measuring Patient Safety Culture in Riyadh's Hospitals: A Comparison between Public and Private Hospitals J Egypt Public Health Assoc 2009; Vol. 84 No. 5 \& 6.

31. El-Jardali F, Sheikh F, Garcia NA, Jamal D, and Abdo A Patient safety culture in a large teaching hospital in Riyadh: baseline assessment, comparative analysis and opportunities for improvement. BMC Health Services Research 2014;14:122 http://www.biomedcentral.com/14726963/14/122 
Table (1): Staff Category of The Studied Participants in Relation to Their Hospital Unit.

\begin{tabular}{|l|r|r|r|r|}
\hline Hospital unit & \multicolumn{1}{|c|}{$\begin{array}{c}\text { Physician } \\
(N=157)\end{array}$} & $\begin{array}{c}\text { Para- } \\
\text { medical } \\
\text { personnel } \\
(N=208)\end{array}$ & $\begin{array}{c}\text { Non- } \\
\text { medical } \\
\text { personnel } \\
(N=33)\end{array}$ & $\begin{array}{c}\text { TOTAL } \\
\text { N (\%) }\end{array}$ \\
\hline Surgery & $28(17.8)$ & $32(15.4)$ & $2(6.1)$ & $62(15.6)$ \\
\hline Medicine & $26(16.6)$ & $48(23.1)$ & $6(18.2)$ & $80(20.1)$ \\
\hline Pharmacy & $1(0.6)$ & $10(4.8)$ & $4(12.1)$ & $15(3.8)$ \\
\hline Pediatrics & $15(9.6)$ & $29(13.9)$ & $2(6.1)$ & $46(11.6)$ \\
\hline Obstetrics \& Gynecology & $14(8.9)$ & $21(10.1)$ & $3(9.1)$ & $38(9.5)$ \\
\hline Emergency & $0(0.0)$ & $5(2.4)$ & $0(0.0)$ & $5(1.3)$ \\
\hline Intensive care (Any type) & $4(2.5)$ & $12(5.8)$ & $0(0.0)$ & $16(4.0)$ \\
\hline Psychiatry & $6(3.8)$ & $3(1.4)$ & $0(0.0)$ & $9(2.3)$ \\
\hline Radiology & $6(3.8)$ & $12(5.8)$ & $3(9.1)$ & $21(5.3)$ \\
\hline Rehabilitation/Physiotherapy & $3(1.9)$ & $8(3.8)$ & $1(3.0)$ & $12(3.0)$ \\
\hline Lab/Blood Bank & $6(3.8)$ & $15(7.2)$ & $4(12.1)$ & $25(6.3)$ \\
\hline OPD* & $24(15.3)$ & $6(2.9)$ & $2(6.1)$ & $32(8.0)$ \\
\hline Anesthesia/OR** & $12(7.6)$ & $5(2.4)$ & $1(3.0)$ & $18(4.5)$ \\
\hline $\begin{array}{l}\text { Many different hospital } \\
\text { units/No specific unit }\end{array}$ & $12(7.6)$ & $2(1.0)$ & $4(12.1)$ & $18(4.5)$ \\
\hline Others & $0(0.0)$ & $0(0.0)$ & $1(3.0)$ & $1(0.3)$ \\
\hline TOTAL N. (\%) & $157(39.5)$ & $208(52.3)$ & $33(8.3)$ & $\mathbf{3 9 8}(\mathbf{1 0 0 . 0})$ \\
\hline
\end{tabular}

${ }^{1}$ (Nurse, technicians...etc. $)^{2}($ Non-medical jobs $) *$ Out Patient Department $* *$ Operation Room

Table (2): Summary of Safety Culture Dimension's Positivity among Studied Participants.

\begin{tabular}{|c|c|c|}
\hline \multicolumn{2}{|c|}{ Safety Culture Dimension } & \multirow{2}{*}{$\begin{array}{c}\text { Safety } \\
\text { Culture } \\
\text { Dimension's } \\
\text { positivity \% } \\
(31.2)\end{array}$} \\
\hline (1) & Communication Openness & \\
\hline (2) & Feedback and Communication about Error & $(32.9)$ \\
\hline (3) & Frequency of Events Reporting & $(23.2)$ \\
\hline (4) & Handoffs \& Transitions & $(38.4)$ \\
\hline (5) & Management Support for Patient Safety & $(34.5)$ \\
\hline (6) & Non-punitive Response to Error & $(30.3)$ \\
\hline (7) & Organizational Learning - Continuous Improvement & $(43.7)$ \\
\hline (8) & Overall Perceptions of Safety & $(39.6)$ \\
\hline (9) & Staffing & $(47.5)$ \\
\hline (10) & $\begin{array}{llll}\text { Supervisor/manager } & \text { Expectations } & \& & \text { Actions } \\
\text { Promoting Safety } & & & \end{array}$ & (53.5) \\
\hline (11) & Teamwork Across Hospital Units & $(39.5)$ \\
\hline (12) & Teamwork Within Hospital Units & $(57.4)$ \\
\hline \multicolumn{3}{|c|}{ Overall Average Positive Response Score $=39.3 \%$} \\
\hline \multicolumn{3}{|c|}{ Percentage of Participants in direct interaction with patients $=\underline{87.9 \%}$} \\
\hline
\end{tabular}


Table (3) Patient Safety Grade and Number of Events Reported in Relation to The Staff Position.

\begin{tabular}{|c|c|c|c|c|}
\hline & $\begin{array}{c}\text { Physician } \\
(N=157)\end{array}$ & $\begin{array}{c}\text { Para-medical } \\
\text { personnel }^{\mathbf{1}} \\
(N=208)\end{array}$ & $\begin{array}{c}\text { Non-medical } \\
\text { personnel } \\
(N=33)\end{array}$ & \multirow[t]{2}{*}{ P-value } \\
\hline & $\mathrm{N}(\%)$ & $\mathrm{N}(\%)$ & $\mathbf{N}(\%)$ & \\
\hline \multicolumn{5}{|c|}{ Patient Safety Grade $(N=398)$} \\
\hline Excellent & $10(6.4)$ & $36(17.3)$ & $10(30.3)$ & \multirow{5}{*}{$0.009 *$} \\
\hline Very Good & $39(24.8)$ & $52(25.0)$ & $3(9.1)$ & \\
\hline Acceptable & $67(42.7)$ & $81(38.9)$ & $11(33.3)$ & \\
\hline Poor & $30(19.1)$ & $33(15.9)$ & $6(18.2)$ & \\
\hline Failing & $11(7.0)$ & $6(2.9)$ & $3(9.1)$ & \\
\hline \multicolumn{5}{|c|}{ Number of Events Reported $(N=398)$} \\
\hline Mean \pm SD & $1.90 \pm 1.67$ & $1.73 \pm 1.52$ & $2.42 \pm 2.09$ & 0.074 \\
\hline
\end{tabular}

${ }^{1}$ (Nurse, technicians ...etc.)

$* P \leq 0.05$ were considered significant using one way ANOVA test.

Table (4): Correlations between Patient Safety Culture Dimensions.

\begin{tabular}{|l|c|c|c|c|}
\hline & \multicolumn{2}{|l|}{$\begin{array}{l}\text { Frequency of Events } \\
\text { Reporting }\end{array}$} & \multicolumn{2}{l|}{$\begin{array}{l}\text { Overall Perceptions of } \\
\text { Safety }\end{array}$} \\
\cline { 2 - 5 } & p-value & Spearman's r & p-value & Spearman's r \\
\hline Communication Openness & $0.001^{*}$ & 0.362 & $0.001^{*}$ & 0.178 \\
\hline $\begin{array}{l}\text { Feedback and Communication about } \\
\text { Error }\end{array}$ & $0.001^{*}$ & 0.337 & $0.001^{*}$ & 0.235 \\
\hline Handoffs \& Transitions & 0.890 & 0.007 & $0.001^{*}$ & 0.531 \\
\hline Management Support for Patient Safety & $0.001^{*}$ & 0.268 & $0.005^{*}$ & 0.142 \\
\hline Non-punitive Response to Error & $0.025^{*}$ & 0.112 & $0.001^{*}$ & 0.234 \\
\hline $\begin{array}{l}\text { Organizational Learning - Continuous } \\
\text { Improvement }\end{array}$ & $0.001^{*}$ & 0.207 & $0.001^{*}$ & 0.347 \\
\hline Staffing Expectations \& & $0.022^{*}$ & 0.115 & $0.001^{*}$ & 0.239 \\
\hline $\begin{array}{l}\text { Supervisor/manager } \\
\text { Actions Promoting Safety }\end{array}$ & $0.001^{*}$ & 0.215 & $0.001^{*}$ & 0.232 \\
\hline Teamwork Across Hospital Units & $0.001^{*}$ & 0.222 & $0.001^{*}$ & 0.369 \\
\hline Teamwork Within Hospital Units & $0.028^{*}$ & 0.110 & 0.594 & -0.027 \\
\hline
\end{tabular}

$* P$-value $\leq 0.05$ is considered significant using $\chi^{2}$. 